\title{
Role of Antithrombotic Therapy and Nonsteroidal Anti-inflammatory Drug Use in Bleeding Gastroduodenal Ulcers
}

\author{
Shohei Shimizu, Shinichi Nakamura, Maiko Kishino, Hiroyuki Konishi and Keiko Shiratori
}

\begin{abstract}
Objective The aim of this study was to analyze the effects of anti-thrombotic therapy and nonsteroidal antiinflammatory drugs (NSAIDs) on gastroduodenal bleeding.

Patients and Methods The study subjects were 544 patients (421 males and 123 females, mean age, 64.2 years) who were treated endoscopically for bleeding gastroduodenal ulcers from January 1995 to August 2008. Of the 544 patients, $276(50.7 \%)$ had a history of treatment for $\geq 1$ month with an antithrombotic agent or NSAIDs, including low-dose aspirin $(n=94)$, other NSAIDs $(n=91)$, warfarin $(n=43)$, or any combination of the three (combination treatment group; $\mathrm{n}=48$ ). On the other hand, 268 patients had not previously received any of these drugs (control group). Clinical features and endoscopic therapeutic results were assessed and compared.

Results Helicobacter pylori infection was detected in 187 of the $241(77.6 \%)$ patients examined. Of the 544 patients, 199 (36.6\%) attended the Department of Cardiology or Cardiovascular Surgery, and 170 (31.3\%) patients were already being treated with antiulcer medication, including proton pump inhibitors $(\mathrm{n}=$ $18[3.3 \%])$. Forty (7.4\%) patients suffered from rebleeding after intervention; the incidence of ulcer rebleeding was not significantly different between patients being treated with any such drugs (4.7\% [13/276]) and those that had not previously received any antithrombotic agent or NSAIDs (10.1\% [27/268]).

Conclusion Antithrombotic therapy and NSAIDs use contributed to bleeding in 50.7\% of patients with gastroduodenal ulcers. These drugs are a major cause of ulcer bleeding, but are not necessarily considered a risk factor for rebleeding after endoscopic hemostasis.
\end{abstract}

Key words: antithrombotic therapy, gastrointestinal bleeding, low-dose aspirin, nonsteroidal antiinflammatory drugs (NSAIDs), warfarin

(Inter Med 48: 631-637, 2009)

(DOI: 10.2169/internalmedicine.48.1793)

\section{Introduction}

The rapid increase in the elderly population in recent years has been associated with the increased use of nonsteroidal anti-inflammatory drugs (NSAIDs), antithrombotic agents, and anticoagulants. This is partly due to recommendations by various neurological and cardiovascular societies that antiplatelet agents should be used for the prevention of ischemic stroke or ischemic heart disease $(1,2)$. In Japan, the use of low-dose aspirin for these conditions has been progressively increasing since antiplatelet therapy with lowdose aspirin was first covered by the National Health Insurance Scheme in 2000. Anticoagulants such as warfarin have also gained wide acceptance for the prevention of cardioembolic stroke secondary to atrial fibrillation.

At orthopedic clinics, NSAIDs are frequently prescribed for patients with osteoporotic lumbar spondylosis and other painful conditions. In North America and Europe, low-dose aspirin is reported to cause serious adverse effects, such as gastrointestinal bleeding and perforation, with an occasional fatal outcome. Garcia-Rodriguez et al (3) reported the re- 
Table 1. Clinical Features of 544 Patients with Gastroduodenal Ulcer Bleeding Treated by Endoscopic Procedures

\begin{tabular}{|c|c|c|c|c|c|c|c|}
\hline & $\begin{array}{l}\text { All patients } \\
(\mathrm{n}=544)\end{array}$ & $\begin{array}{c}\text { Low-dose } \\
\text { Aspirin ( } \mathrm{n}=94)\end{array}$ & $\begin{array}{l}\text { NSAIDs } \\
(\mathrm{n}=91)\end{array}$ & $\begin{array}{l}\text { Warfarin } \\
(\mathrm{n}=43)\end{array}$ & $\begin{array}{c}\text { Combination } \\
(\mathrm{n}=48)\end{array}$ & $\begin{array}{l}\text { Control } \\
(\mathrm{n}=268)\end{array}$ & $\mathrm{p}$ value \\
\hline Male / Female & $421 / 123$ & $73 / 21$ & $56 / 35$ & $36 / 7$ & $41 / 7$ & $215 / 53$ & $\mathrm{p}=0.0033$ \\
\hline Age (years, mean \pm SD) & $64.2 \pm 14.2$ & $69.1 \pm 11.3$ & $64.2 \pm 12.1$ & $66.0 \pm 13.4$ & $71.2 \pm 7.2$ & $61.0 \pm 15.9$ & $\mathrm{p}<0.0001$ \\
\hline Site of ulcer & & & & & & & NS \\
\hline Gastric & $394(72.4 \%)$ & $70(74.5 \%)$ & $68(74.7 \%)$ & $36(83.7 \%)$ & $39(81.3 \%)$ & $181(67.5 \%)$ & \\
\hline Upper/Middle/Lower & $153 / 199 / 42$ & $30 / 31 / 9$ & $25 / 31 / 12$ & $9 / 23 / 4$ & $17 / 16 / 6$ & $72 / 98 / 11$ & \\
\hline Duodenal & $125(23.0 \%)$ & $20(21.3 \%)$ & $18(19.8 \%)$ & $6(14.0 \%)$ & $9(18.8 \%)$ & $72(26.9 \%)$ & \\
\hline Stomal & $25(4.6 \%)$ & $4(4.3 \%)$ & $5(5.5 \%)$ & $1(2.3 \%)$ & $0(0.0 \%)$ & $15(5.6 \%)$ & \\
\hline Forrest classification & & & & & & & $\mathrm{p}=0.0245$ \\
\hline Ia & $84(15.4 \%)$ & $9(9.6 \%)$ & $14(15.4 \%)$ & $7(16.3 \%)$ & $5(10.4 \%)$ & $49(18.3 \%)$ & \\
\hline $\mathrm{Ib}$ & $147(27.0 \%)$ & $28(29.8 \%)$ & $21(23.1 \%)$ & $20(46.5 \%)$ & $17(35.4 \%)$ & $61(22.8 \%)$ & \\
\hline IIa & $313(57.5 \%)$ & $57(60.6 \%)$ & $56(61.5 \%)$ & $16(37.2 \%)$ & $26(54.2 \%)$ & $158(59.0 \%)$ & \\
\hline
\end{tabular}

sults of meta-analysis of cohort and nested case-control studies, which showed that oral aspirin was significantly associated with serious upper gastrointestinal complications (odds ratio of 2.9 and $95 \%$ confidence interval [CI] of 2.33.9). In Japan, the increased incidence of gastrointestinal bleeding associated with antithrombotic, anticoagulant, or NSAIDs therapy has become a public health problem $(4,5)$. In a case-control study, Sakamoto et al (6) found that gastrointestinal bleeding was 5.5 times more frequent in aspirin users and 7.7 times more frequent in regular aspirin users compared with controls. In daily practice, gastroenterologists encounter numerous patients with gastrointestinal complications (e.g., peptic ulcer and bleeding) who are on antithrombotic or anticoagulant therapy, although they form only a small proportion of patients receiving such therapy from prescribing neurologists or cardiologists. We retrospectively reviewed the medical records of patients treated for bleeding gastroduodenal ulcers at our clinic and analyzed the association between upper gastrointestinal complications and antithrombotic therapy.

\section{Subjects and Methods}

A retrospective review was performed of 544 patients treated endoscopically for bleeding gastroduodenal ulcers (excluding iatrogenic ulcers caused by endoscopic mucosal resection or other procedures) at the Institute of Gastroenterology of Tokyo Women's Medical University (Tokyo, Japan) from January 1995 to August 2008. They included 421 males and 123 females, with a mean age of 64.2 years. The cause of bleeding was confirmed endoscopically to be gastric ulcer located in the upper stomach (cardia/upper body) $(n=153)$, middle stomach (lower body/angle) $(n=199)$, or lower stomach (vestibule) $(\mathrm{n}=42)$ in 394 patients $(72.4 \%)$; duodenal ulcer in 125 patients $(23.0 \%)$; and stomal ulcer in 25 patients $(4.6 \%)$. None of the patients was on hemodialysis. Based on the Forrest classification (7) of bleeding peptic ulcer, 84 patients $(15.4 \%$ ) had type Ia bleeding (arterial spurting), 147 patients (27.0\%) had type Ib bleeding (oozing), and 313 patients (57.5\%) had type IIa bleeding (a visible vessel in the base of an ulcer and signs of recent bleeding) (Table 1).

After undergoing endoscopic hemostasis, all patients were hospitalized and managed conventionally (nil orally, intravenous fluids, and a proton pump inhibitor). At 24-48 hours after endoscopic intervention, each patient underwent a second-look endoscopy.

Of the 544 patients, 276 patients $(50.7 \%)$ had a history of treatment for $\geq 1$ month with an antithrombotic agent or NSAIDs; including low-dose aspirin (low-dose aspirin group; $n=94$ ), other NSAIDs (NSAIDs group; $n=91$ ), warfarin (warfarin group; $n=43$ ), or any combination of lowdose aspirin, non-aspirin NSAIDs, and warfarin (combination treatment group; $n=48$ ). These groups of patients were compared with those who had not previously received any of these drugs (control group; $n=268$ ) with respect to the prevalence of Helicobacter pylori $(H$. pylori) infection, the specialty of their attending physician (e.g., nongastroenterological physicians who prescribed antithrombotic/NSAIDs medications and/or referred the patients for emergency gastroduodenal endoscopy), anti-ulcer medications, endoscopic interventions, and incidence of ulcer rebleeding. $H$. pylori infection was diagnosed based on detection of anti-H. pylori antibody in the urine. Rebleeding was diagnosed by definitive endoscopic evidence of ulcer bleeding or other clinical evidence of gastrointestinal bleeding (e.g., hematemesis or melena) in conjunction with a decrease of hemoglobin by at least $2.0 \mathrm{~g} / \mathrm{dL}$.

\section{Statistical analysis and ethical consideration}

The results are expressed as number of patients (percentage) and age is presented as mean \pm standard deviation. The Kruskal-Wallis test and $\chi^{2}$ test were used to analyze differences between groups. A $P$ value less than 0.05 denoted the presence of a statistically significant difference. The JMP Statistical Discovery (SAS, version 7, SAS Institute Japan 
Table 2. Results of Various Factors and Rebleeding Rate after Endoscopic Hemostasis

\begin{tabular}{|c|c|c|c|c|c|c|c|}
\hline & $\begin{array}{l}\text { All patients } \\
(\mathrm{n}=544)\end{array}$ & $\begin{array}{c}\text { Low-dose } \\
\text { Aspirin }(\mathrm{n}=94)\end{array}$ & $\begin{array}{l}\text { NSAIDs } \\
(\mathrm{n}=91)\end{array}$ & $\begin{array}{l}\text { Warfarin } \\
(\mathrm{n}=43)\end{array}$ & $\begin{array}{l}\text { Combination } \\
\quad(\mathrm{n}=48)\end{array}$ & $\begin{array}{l}\text { Control } \\
(\mathrm{n}=268)\end{array}$ & $\mathrm{p}$ value \\
\hline Positive rate of $H$. pylori infection & $77.6 \%(187 / 241)$ & $82.5 \%(33 / 40)$ & $74.4 \%(32 / 43)$ & $55.0 \%(11 / 20)$ & $63.2 \%(12 / 19)$ & $83.2 \%(99 / 119)$ & NS \\
\hline \multicolumn{8}{|l|}{ Referring Department } \\
\hline Cardiology, Cardiovascular & $199(36.6 \%)$ & $54(57.4 \%)$ & $14(15.4 \%)$ & $37(86.0 \%)$ & $39(81.3 \%)$ & $55(20.5 \%)$ & \\
\hline Diabetes & $39(7.2 \%)$ & $12(12.8 \%)$ & $3(3.3 \%)$ & $0(0.0 \%)$ & $0(0.0 \%)$ & $24(9.0 \%)$ & \\
\hline Neurology, Neurovascular & $37(6.8 \%)$ & $18(19.1 \%)$ & $7(7.7 \%)$ & $4(9.3 \%)$ & $4(8.3 \%)$ & $8(3.0 \%)$ & \\
\hline Nephrology, Urology & $28(5.1 \%)$ & $6(6.4 \%)$ & $3(3.3 \%)$ & $1(2.3 \%)$ & $2(4.2 \%)$ & $16(6.0 \%)$ & \\
\hline Orthopedics, Rheumatology & $28(5.1 \%)$ & $0(0.0 \%)$ & $18(19.8 \%)$ & $0(0.0 \%)$ & $3(6.3 \%)$ & $7(2.6 \%)$ & \\
\hline Others & $33(6.1 \%)$ & $1(1.1 \%)$ & $10(11.0 \%)$ & $1(2.6 \%)$ & $0(0.0 \%)$ & $21(7.8 \%)$ & \\
\hline \multicolumn{8}{|l|}{ Medications for GI tract } \\
\hline Proton-pump inhibitor & $18(3.3 \%)$ & $4(4.3 \%)$ & $4(4.4 \%)$ & $2(4.7 \%)$ & $2(4.2 \%)$ & $6(2.2 \%)$ & \\
\hline $\mathrm{H}_{2}$-receptor antagonist & $64(11.8 \%)$ & $15(16.0 \%)$ & $14(15.4 \%)$ & $3(7.0 \%)$ & $5(10.4 \%)$ & $27(10.1 \%)$ & \\
\hline Prostaglandin drugs & $5(0.9 \%)$ & $2(2.1 \%)$ & $1(1.1 \%)$ & $0(0.0 \%)$ & $2(4.2 \%)$ & $0(0.0 \%)$ & \\
\hline Cytoprotective drugs & $83(15.3 \%)$ & $15(16.0 \%)$ & $19(20.9 \%)$ & $11(25.6 \%)$ & $16(33.3 \%)$ & $22(8.2 \%)$ & \\
\hline None & $234(43.0 \%)$ & $40(42.6 \%)$ & $26(28.6 \%)$ & $13(30.2 \%)$ & $21(43.8 \%)$ & $134(50.0 \%)$ & \\
\hline Unknown & $140(25.7 \%)$ & $18(19.1 \%)$ & $27(29.7 \%)$ & $14(32.6 \%)$ & $2(4.2 \%)$ & $79(29.5 \%)$ & \\
\hline Endoscopic treatment & & & & & & & NS \\
\hline Electrocoagulation & $482(88.6 \%)$ & $85(90.4 \%)$ & $82(90.1 \%)$ & $35(81.3 \%)$ & $40(83.3 \%)$ & $240(90.0 \%)$ & \\
\hline Clipping & $46(8.5 \%)$ & $9(9.6 \%)$ & $8(8.8 \%)$ & $5(11.6 \%)$ & $5(10.4 \%)$ & $19(7.1 \%)$ & \\
\hline Others & $16(2.9 \%)$ & $0(0.0 \%)$ & $1(1.1 \%)$ & $3(7.0 \%)$ & $3(6.3 \%)$ & $9(3.4 \%)$ & \\
\hline Rebleeding & $40(7.4 \%)$ & $5(5.3 \%)$ & $5(5.5 \%)$ & $0(0.0 \%)$ & $3(6.3 \%)$ & $27(10.1 \%)$ & NS \\
\hline Surgical operation required & $6(1.1 \%)$ & $2(2.1 \%)$ & $1(1.1 \%)$ & $0(0.0 \%)$ & $0(0.0 \%)$ & $3(1.1 \%)$ & NS \\
\hline
\end{tabular}

Co.) program was used for statistical analysis. Written informed consent was obtained from all patients before endoscopic procedures.

\section{Results}

A summary of the results for groups stratified according to previous antithrombotic/NSAIDs therapy is given in Table 2 .

Prevalence of $\boldsymbol{H}$. pylori infection: $H$. pylori infection was detected in 187 of the 241 patients $(77.6 \%)$ examined. The prevalence of $H$. pylori infection was not significantly different among the groups stratified according to previous antithrombotic/NSAIDs therapy, being $82.5 \%$ in the low-dose aspirin group, $74.4 \%$ in the non-aspirin NSAIDs group, $55.0 \%$ in the warfarin group, $63.2 \%$ in the combination treatment group, and $83.2 \%$ in the untreated control group.

Specialties of the attending physicians: Of the 544 patients, 199 (36.6\%) attended the Department of Cardiology or Cardiovascular Surgery. The following specialties, in descending order of frequency, were involved in the management of patients: diabetologists $(n=39$ [7.2\%]), neurologists/ neurovascular surgeons $(n=37[6.8 \%])$, nephrologists/urologists $(n=28[5.1 \%])$, orthopedic surgeons/rheumatologists $(n=28[5.1 \%])$, and psychiatrists $(n=9[1.7 \%])$. More than $50 \%$ (a significantly higher percentage compared with the controls) of the low-dose aspirin and warfarin groups attended the Department of Cardiology or Cardiovascular Surgery. The next most frequent specialties of the attending physicians were neurology/neurovascular surgery and diabe- tology. This indicates that most patients who were treated with low-dose aspirin or warfarin were being managed for atherosclerosis or thrombosis. Of the 91 patients treated with any NSAIDs, 18 (19.8\%) attended the Department of Orthopedics/Rheumatology, which was the most frequent specialty of the attending physicians.

Anti-ulcer medications: Among patients with a bleeding peptic ulcer, 170 of the 544 patients $(31.3 \%)$ were already receiving anti-ulcer medications, including proton pump inhibitors $\left(\mathrm{n}=18\right.$ [3.3\%]), histamine $\mathrm{H}_{2}$-receptor antagonists $(\mathrm{n}=64[11.8 \%])$ (Table 3), prostaglandins $(\mathrm{n}=5$ [0.9\%]), and other cytoprotective drugs $(n=83$ [15.3\%]). Anti-ulcer medications were not prescribed in 234 patients $(43.0 \%)$, and no data were available for the remaining 140 patients $(25.7 \%)$.

Endoscopic intervention and ulcer rebleeding: The procedure used to achieve endoscopic hemostasis was electrocoagulation in 482 patients $(88.6 \%)$, clipping in 46 patients $(8.5 \%)$, and other procedures in 16 patients $(2.9 \%)$. Forty patients $(7.4 \%)$ suffered from rebleeding after intervention. The incidence of ulcer rebleeding was not significantly different between patients treated with any such drugs $(5.3 \%$ [5/94] for low-dose aspirin group, 5.5\% [5/91] for nonaspirin NSAIDs group, $0.0 \%$ [0/43] for warfarin group, and $6.3 \%$ [3/48] for the combination treatment group), and those that had not previously received any antithrombotic agent or NSAIDs (10.1\% [27/268]). Table 4 summarizes the clinical details of 40 rebleeding patients and 504 no rebleeding patients after initial hemostasis. Of the 40 patients with rebleeding, 37 (92.5\%) were males. The incidence of rebleeding was higher in duodenal ulcer and type Ia on the 
Table 3. Clinical Details of Patients Treated with Proton-pump Inhibitors and $\mathrm{H}_{2}$-receptor Antagonists

\begin{tabular}{|c|c|c|}
\hline & $\begin{array}{l}\text { Proton-pump inhibitors } \\
\qquad(\mathrm{n}=18)\end{array}$ & $\begin{array}{l}\text { H2-receptor antagonists } \\
\qquad(\mathrm{n}=64)\end{array}$ \\
\hline Male / Female & $14 / 4$ & $47 / 17$ \\
\hline Age (years, mean \pm SD) & $65.4 \pm 16.2$ & $64.3 \pm 15.0$ \\
\hline \multicolumn{3}{|l|}{ Site of ulcer } \\
\hline Gastric & $13(72.2 \%)$ & $48(75.0 \%)$ \\
\hline Upper/Middle/Lower & $4 / 5 / 4$ & $12 / 31 / 5$ \\
\hline Duodenal & $3(16.7 \%)$ & $12(18.8 \%)$ \\
\hline Stomal & $2(11.1 \%)$ & $4(6.3 \%)$ \\
\hline \multicolumn{3}{|l|}{ Forrest classification } \\
\hline Ia & $5(27.8 \%)$ & $10(15.6 \%)$ \\
\hline $\mathrm{Ib}$ & $7(38.9 \%)$ & $15(23.4 \%)$ \\
\hline IIa & $6(33.3 \%)$ & $39(60.9 \%)$ \\
\hline Positive rate of $H$. pylori & $55.0 \%(5 / 9)$ & $78.6 \%(22 / 28)$ \\
\hline \multicolumn{3}{|l|}{ infection } \\
\hline \multicolumn{3}{|l|}{ Referring Department } \\
\hline Cardiology, Cardiovascular & $6(33.3 \%)$ & $26(40.6 \%)$ \\
\hline Diabetes & $3(16.7 \%)$ & $4(6.3 \%)$ \\
\hline Neurology, Neurovascular & $1(5.6 \%)$ & $2(3.1 \%)$ \\
\hline Nephrology, Urology & $2(11.1 \%)$ & $2(3.1 \%)$ \\
\hline Orthopedics, Rheumatology & $0(0.0 \%)$ & $3(4.7 \%)$ \\
\hline Others & $2(11.1 \%)$ & $4(6.3 \%)$ \\
\hline \multicolumn{3}{|l|}{ Antithrombotic and NSAIDs use } \\
\hline Low-dose Aspirin & $4(22.2 \%)$ & $15(23.4 \%)$ \\
\hline NSAIDs & $4(22.2 \%)$ & $14(21.9 \%)$ \\
\hline Warfarin & $2(11.1 \%)$ & $3(4.7 \%)$ \\
\hline Combination & $2(11.1 \%)$ & $5(7.8 \%)$ \\
\hline \multicolumn{3}{|l|}{ Endoscopic treatment } \\
\hline Electrocoagulation & $13(72.2 \%)$ & $57(89.1 \%)$ \\
\hline Clipping & $4(22.2 \%)$ & $7(10.9 \%)$ \\
\hline Others & $1(5.6 \%)$ & $0(0.0 \%)$ \\
\hline Rebleeding & $1(5.6 \%)$ & $8(12.5 \%)$ \\
\hline
\end{tabular}

Forrest classification. Six patients $(1.1 \%)$ eventually required surgical treatment, including 4 with difficulty in achieving endoscopic hemostasis ( 2 with gastric ulcer, 1 with duodenal ulcer, and 1 with stomal ulcer) and 2 with gastroduodenal perforation. All four patients in whom endoscopic hemostasis was difficult to achieve had conditions that interfered with permanent hemostasis, such as recurrent vestibular ulcers or chronic leukemia.

\section{Discussion}

In the present study, we retrospectively reviewed the clinicopathological features, baseline treatment, and outcome of endoscopic hemostasis in patients managed at our department for gastroduodenal ulcer bleeding to determine the relationship between gastroduodenal bleeding and previous antithrombotic or NSAIDs therapy. The results showed that $50.7 \%$ of patients were on antithrombotic agents or NSAIDs and most of them attended the department that provided care for atherosclerotic and/or thrombotic conditions. An un- expectedly small number of patients treated for bleeding gastrointestinal ulcers were regularly managed by orthopedic surgeons, who are generally thought to frequently prescribe NSAIDs. Although NSAIDs other than aspirin can induce gastric mucosal lesions and ulcers, these drugs are unlikely to cause bleeding because of their less potent antiplatelet activity compared with that of low-dose aspirin (8).

Aspirin is an NSAID that inhibits the inducible isoenzyme of cyclooxygenase (cyclooxygenase 1 [COX-1]), a key enzyme of the arachidonic acid cascade, and thereby suppresses the synthesis of thromboxane A2, which results in its antiplatelet effect. Yeomans et al (9) performed upper gastrointestinal tract endoscopy in 187 patients who were receiving low-dose aspirin for the prevention of cardiovascular events and detected peptic ulcers (mucosal defects $\geq 3 \mathrm{~mm}$ in diameter) in $20(10.7 \%)$ patients and mucosal erosions in $118(63.1 \%)$ patients. Subsequent follow-up showed that peptic ulcers occurred in low-dose aspirin users at an annual incidence rate of $28 \%$, although only about $20 \%$ of the patients with aspirin-induced peptic ulcers had symptoms (e.g., 
Table 4. Comparison of 40 Patients with Rebleeding and 504 Patients without Rebleeding after Initial Hemostasis

\begin{tabular}{|c|c|c|c|c|c|}
\hline & \multicolumn{2}{|c|}{ Rebleeding $\quad(\mathrm{n}=40)$} & \multicolumn{2}{|c|}{ No rebleeding $\quad(n=504)$} & \multirow[b]{2}{*}{$\mathrm{p}$ value } \\
\hline & $\begin{array}{c}\text { Antithrombotic, } \\
\text { NSAIDs users }(n=13)\end{array}$ & $\begin{array}{l}\text { No drug users } \\
\qquad(\mathrm{n}=27)\end{array}$ & $\begin{array}{l}\text { Antithrombotic, } \\
\text { NSAIDs users } \\
\quad(n=263)\end{array}$ & $\begin{array}{l}\text { No drug users } \\
\qquad(\mathrm{n}=241)\end{array}$ & \\
\hline Male / Female & $13 / 0$ & $24 / 3$ & $193 / 70$ & $191 / 50$ & NS \\
\hline Age (years, mean \pm SD) & $65.2 \pm 12.5$ & $63.5 \pm 11.8$ & $67.5 \pm 11.6$ & $60.7 \pm 16.3$ & $<0.0001$ \\
\hline Site of ulcer & & & & & NS \\
\hline Gastric & $9(69.2 \%)$ & $15(55.6 \%)$ & $204(77.6 \%)$ & $166(68.9 \%)$ & \\
\hline Upper/Middle/Lower & $3 / 5 / 1$ & $4 / 10 / 1$ & $78 / 96 / 30$ & $68 / 88 / 10$ & \\
\hline Duodenal & $3(30.0 \%)$ & $9(33.3 \%)$ & $50(19.0 \%)$ & $63(26.1 \%)$ & \\
\hline Stomal & $1(10.0 \%)$ & $3(11.1 \%)$ & $9(3.4 \%)$ & $12(5.0 \%)$ & \\
\hline Forrest classification & & & & & NS \\
\hline Ia & $4(30.8 \%)$ & $5(18.5 \%)$ & $31(11.8 \%)$ & $44(18.3 \%)$ & \\
\hline $\mathrm{Ib}$ & $3(23.1 \%)$ & $8(29.6 \%)$ & $83(31.6 \%)$ & $53(22.0 \%)$ & \\
\hline IIa & $6(46.2 \%)$ & $14(51.9 \%)$ & $149(56.7 \%)$ & $144(59.8 \%)$ & \\
\hline $\begin{array}{l}\text { Positive rate of } H . \text { pylori } \\
\text { infection }\end{array}$ & $33.3 \%(1 / 3)$ & $80.0 \%(4 / 5)$ & $73.1 \%(87 / 119)$ & $83.3 \%(95 / 114)$ & NS \\
\hline \multicolumn{6}{|l|}{ Referring Department } \\
\hline Cardiology, Cardiovascular & $8(61.5 \%)$ & $5(18.5 \%)$ & $136(51.7 \%)$ & $50(20.7 \%)$ & \\
\hline Diabetes & $0(0.0 \%)$ & $3(11.1 \%)$ & $15(5.7 \%)$ & $21(8.7 \%)$ & \\
\hline Neurology, Neurovascular & $0(0.0 \%)$ & $1(3.7 \%)$ & $29(11.0 \%)$ & $7(2.9 \%)$ & \\
\hline Nephrology, Urology & $1(7.7 \%)$ & $2(7.4 \%)$ & $11(4.2 \%)$ & $14(5.8 \%)$ & \\
\hline Orthopedics, Rheumatology & $0(0.0 \%)$ & $0(0.0 \%)$ & $21(8.0 \%)$ & $7(2.9 \%)$ & \\
\hline Others & $1(7.7 \%)$ & $5(18.5 \%)$ & $11(4.2 \%)$ & $16(6.6 \%)$ & \\
\hline \multicolumn{6}{|l|}{ Medication for GI tract } \\
\hline Proton-pump inhibitor & $1(7.7 \%)$ & $0(0.0 \%)$ & $11(4.2 \%)$ & $6(2.5 \%)$ & \\
\hline $\mathrm{H}_{2}$-receptor antagonist & $3(23.1 \%)$ & $5(18.5 \%)$ & $34(12.9 \%)$ & $22(9.1 \%)$ & \\
\hline Prostaglandin drugs & $0(0.0 \%)$ & $0(0.0 \%)$ & $5(1.9 \%)$ & $0(0.0 \%)$ & \\
\hline Cytoprotective drugs & $1(7.7 \%)$ & $3(11.1 \%)$ & $60(22.8 \%)$ & $19(7.9 \%)$ & \\
\hline None & $7(53.8 \%)$ & $6(22.2 \%)$ & $93(35.4 \%)$ & $128(53.1 \%)$ & \\
\hline Unknown & $1(7.7 \%)$ & $13(48.1 \%)$ & $60(22.8 \%)$ & $66(27.4 \%)$ & \\
\hline Initial endoscopic treatment & & & & & NS \\
\hline Electrocoagulation & $11(84.6 \%)$ & $23(85.2 \%)$ & $231(87.8 \%)$ & $217(90.0 \%)$ & \\
\hline Clipping & $1(7.7 \%)$ & $1(3.7 \%)$ & $26(9.9 \%)$ & $18(7.5 \%)$ & \\
\hline Others & $1(7.7 \%)$ & $3(11.1 \%)$ & $6(2.3 \%)$ & $6(2.5 \%)$ & \\
\hline
\end{tabular}

epigastric pain). Niv et al (10) also detected gastroduodenal ulcers and/or erosions by endoscopy in $47.8 \%$ of 46 asymptomatic patients treated with low-dose aspirin and concluded that a high percentage of asymptomatic patients have aspirin-induced gastroduodenal ulcers or other mucosal lesions. Serrano et al (11) identified gastrointestinal bleeding in 41 patients $(4.5 \%)$ out of 903 patients on low-dose aspirin who were followed up for a mean of 45 months. Weisman and Graham (12) conducted a meta-analysis of six placebo-controlled studies involving a total of 6,300 patients on low-dose aspirin, and reported that the relative risk of gastrointestinal bleeding was 2.5 (95\% CI: 1.4-4.7) for patients receiving low-dose aspirin $(1.31 \%)$ compared with those receiving placebo $(0.55 \%)$. Derry and Loke (13) conducted a meta-analysis of 24 placebo-controlled studies involving a total of 66,000 patients receiving low-dose aspirin, and they also reported that gastrointestinal bleeding was more frequent in patients on low-dose aspirin than in placebo recipients $(2.47 \%$ vs. $1.42 \%$ ) (odds ratio of 1.68 [95\%

\section{CI: 1.51-1.88]).}

Here, $40(7.4 \%)$ of the 544 patients suffered from rebleeding after initial intervention. Contrary to our expectation, the incidence of ulcer rebleeding after endoscopic hemostasis was higher in patients who had not previously received antithrombotic or NSAIDs therapy (10\%) than in those previously treated with such drugs (5-6\%). The causes of ulcer rebleeding may include technical factors related to endoscopic intervention and the general condition of the patient. However, it seems that previous antithrombotic or NSAIDs therapy is unlikely to increase the risk of rebleeding after endoscopic hemostasis. Travis et al (14) identified six risk factors for rebleeding following endoscopic therapy for non-variceal upper gastrointestinal bleeding. These include failure to use a proton-pump inhibitor post-procedure, endoscopically demonstrated bleeding, peptic ulcer as the bleeding site, treatment with epinephrine monotherapy, postprocedure heparin use, moderate or severe cirrhosis. It is also noteworthy that none of the patients who were being 
treated with warfarin alone suffered from rebleeding. This may be explained by the fact that warfarin does not damage the gastric mucosa, which permits maintenance of hemostasis and avoids rebleeding in patients on warfarin therapy.

Warfarin exerts its anticoagulant and antithrombotic effects by inhibiting the synthesis of vitamin K-dependent coagulation factors and warfarin therapy could increase the likelihood of bleeding events, including gastrointestinal hemorrhage. The incidence of bleeding complications in warfarin users has been reported to be $4.8 \%$. The gastrointestinal tract is most frequently affected $(31.5 \%)$, followed by bleeding into the soft tissues, urinary tract bleeding (hematuria), intracranial bleeding, and epistaxis $(15,16)$. Sam et al (17) studied 393 patients who were being treated with antithrombotic agents for atrial fibrillation and detected serious gastrointestinal bleeding in $65(17 \%)$ patients during 5 years of follow-up. Interestingly, they reported that the risk of serious gastrointestinal bleeding was increased by treatment with aspirin (odds ratio: 3.5 [95\% CI: 1.4-8.7]) and warfarin (odds ratio: 3.9 [95\% CI: 1.5-10.3]) in female patients, but not in male patients.

During treatment with antithrombotic agents or NSAIDs, it is also important to take appropriate measures to counter the increased risk of peptic ulcer or gastrointestinal bleeding. In the present series, only $31.3 \%$ of the patients were being treated with anti-ulcer medications when they developed a bleeding ulcer. Concomitant treatment with a proton pump inhibitor or histamine $\mathrm{H}_{2}$-receptor antagonist did not prevent gastroduodenal ulcer bleeding in 10-20\% of patients on antithrombotic or NSAIDs therapy. The Japanese Guidelines for the Management of Gastric Ulcers recommend the administration of prostaglandins, proton pump inhibitors, or high-dose histamine $\mathrm{H}_{2}$-receptor antagonists to prevent ulceration by low-dose aspirin or NSAIDs (18). The guidelines also suggest that the incidence of gastrointestinal complications due to non-aspirin NSAIDs may be reduced by employing COX-2 selective COX inhibitors and caution that inhibition of COX-1 could cause NSAIDs-induced gastrointestinal mucosal injury.

The association of NSAIDs-induced ulceration with $H$. pylori infection, and the indications for the use of $H$. pylori eradication therapy to prevent and treat NSAIDs-induced ulcers, are other issues that deserve attention. Sakamoto et al (6) reported that the odds ratio for upper gastrointestinal tract bleeding was 5.4 among $H$. pylori carriers, 4.9 among NSAIDs users, and 10.4 among $H$. pylori carriers who were also NSAID users, indicating that $H$. pylori infection and use of NSAIDs increase additively the risk of gastroduodenal bleeding. Thus, it is clear that $H$. pylori infection increases the risk of peptic ulceration in patients taking lowdose aspirin or NSAIDs and that $H$. pylori eradication can prevent drug-induced peptic ulceration or reduce its recurrence $(19,20)$.

In conclusion, antithrombotic therapy and NSAIDs use contributed to bleeding in $50.7 \%$ of patients with gastroduodenal ulcers. These drugs are a major cause of ulcer bleeding, but are not necessarily considered a risk factor for rebleeding after endoscopic hemostasis. The current increase in the elderly population will inevitably lead to a more extensive use of antithrombotic agents and NSAIDs, making it important to consider effective countermeasures for the gastrointestinal complications of these medications.

\section{References}

1. Guidelines for management of anticoagulant and antiplatelet therapy in cardiovascular disease. Circ J 68 (Suppl. IV): 2004 (in Japanese).

2. Patrono C, Garcia Rodriguez LA, Landolfi R, et al. Low-dose aspirin for the prevention of atherothrombosis. N Engl J Med 353: 2373-2383, 2005.

3. Garcia-Rodriguez LA, Hernandez-Diaz S, de Abajo FJ. Association between aspirin and upper gastrointestinal complications: systemic review of epidemiologic studies. Br J Clin Pharmacol 52: 563-571, 2001.

4. Ootani H, Iwakiri R, Shimoda R, et al. Role of Helicobacter pylori infection and nonsteroidal anti-inflammatory drug use in bleeding peptic ulcers in Japan. J Gastroenterol 41: 41-46, 2006.

5. Ishikawa S, Inaba T, Noma Y, et al. A clinical study of Japanese patients with severe bleeding ulcers induced by non-steroidal antiinflammatory drugs. Gastroenterol Endosc 49: 314-323, 2007 (in Japanese, Abstract in English).

6. Sakamoto C, Sugano K, Ota S, et al. Case-control study on the association of upper gastrointestinal bleeding and nonsteroidal anti-inflammatory drugs in Japan. Eur J Clin Pharmacol 62: 765772, 2006.

7. Forrest JAN, Finlayson NDC, Sherman DJC. Endoscopy in gastrointestinal bleeding. Lancet 2: 394-397, 1974.

8. Taha AS, Angerson WJ, Knill-Jones RP, et al. Upper gastrointestinal haemorrhage associated with low-dose aspirin and antithrombotic drugs-a 6-year analysis and comparison with non- steroidal anti-inflammatory drugs. Aliment Pharmacol Ther 22: 285-289, 2005.

9. Yeomans ND, Lanas AI, Talley NJ, et al. Prevalence and incidence of gastroduodenal ulcers during treatment with vascular protective doses of aspirin. Aliment Pharmacol Ther 22: 795-801, 2005.

10. Niv Y, Battler A, Abuksis G, et al. Endoscopy in asymptomatic minidose aspirin consumers. Dig Dis Sci 50: 78-80, 2005.

11. Serrano P, Lanas A, Arroyo MT, et al. Risk of upper gastrointestinal bleeding in patients taking low-dose aspirin for the prevention of cardiovascular disease. Aliment Pharmacol Ther 16: 1945-1953, 2002.

12. Weisman SM, Graham DY. Evaluation of the benefits and risks of low-dose aspirin in the secondary prevention of cardiovascular and cerebrovascular events. Arch Intern Med 162: 2197-2202, 2002.

13. Derry S, Loke YK. Risk of gastrointestinal haemorrhage with long term use of aspirin: meta-analysis. Br Med J 321: 1183-1187, 2000.

14. Travis AC, Wasan SK, Saltzman JR. Model to predict rebleeding following endoscopic therapy for non-variceal upper gastrointestinal hemorrhage. J Gastroenterol Hepatol 23: 1505-1510, 2008.

15. Landefeld CS, Goldman L. Major bleeding in outpatients treated with warfarin: incidence and prediction by factors known at the start of outpatients therapy. Am J Med 87: 144-152, 1989.

16. Landefeld CS, Rosenblatt MW, Goldman L. Major bleeding in outpatients treated with warfarin: relation to the prothrombin time 
and important remediable lesions. Am J Med 87: 153-159, 1989.

17. Sam C, Massaro JM, D'Agostino RB, et al. Warfarin and aspirin use and the predictors of major bleeding complications in atrial fibrillation (the Framingham Heart Study). Am J Cardiol 94: 947951, 2004.

18. Guidelines for management of gastric ulcer. 2nd edition. Jiho, 2007 (in Japanese).
19. Lanas A, Scheiman J. Low-dose aspirin and upper gastrointestinal damage: epidemiology, prevention and treatment. Curr Med Res Opin 23: 163-173, 2007.

20. Bhatt DL, Scheiman J, Abraham NS, et al. ACCF/ACG/AHA 2008 Expert consensus document on reducing the gastrointestinal risks of antiplatelet therapy and NSAID use. Am J Gastroenterol 103: 1-18, 2008.

(C) 2009 The Japanese Society of Internal Medicine http://www.naika.or.jp/imindex.html 